\title{
Development and evaluation of a miniaturised method as an aid to the identification of clinically important anaerobic bacteria
}

\author{
PN LEVETT \\ From the Anaerobe Reference Unit, Public Health Laboratory, Luton and Dunstable Hospital, Lewsey Road, \\ Luton LU4 ODZ
}

SUMMARY A miniaturised method for the identification of anaerobic bacteria is described which employs microtitre fermentation tests, a spot indole test and a nitrate reduction disc test. The results obtained are directly comparable with those produced by a standard conventional method in use at present.

Specific identification of anaerobes may require the performance of a wide range of biochemical tests which often include determination of the ability of an isolate to produce acid from a range of fermentable substrates. In the past these tests have presented considerable problems to workers attempting an identification. More recently sophisticated techniques have been developed that permit the identification of anaerobes with a high degree of accuracy; of importance amongst these is the analysis of metabolic end-products by gas-liquid chromatography. ${ }^{1-4}$ However, these methods become laborious and costly when large numbers of isolates are examined. For this reason miniaturised biochemical methods have become popular ${ }^{56}$ and a variety of identification kits are commercially available (API 20A, Becton \& Dickinson Minitek II, Flow Anaerobe-Tek, Microbact 24A). This paper describes the evaluation of such a method that has been developed in this laboratory.

\section{Material and methods}

BACTER IAL ISOLATES

One hundred and twenty-one isolates representing 56 species of 11 genera of anaerobes were studied (Table).

MICROTITRE TRAY METHOD

Base medium

A sloppy base was prepared containing bacteriological peptone (Oxoid L37) $5 \mathrm{~g} / \mathrm{l}$; tryptone (Lab M MC5) $5 \mathrm{~g} / \mathrm{l}$; yeast extract (Oxoid L21) $6 \mathrm{~g} / \mathrm{l}$; New

Accepted for publication 1 September 1983
Zealand agar (Davis) $2 \mathrm{~g} / \mathrm{l}$; salts solution (Holdeman et $\left.a l^{2}\right) \quad 40 \mathrm{ml} / \mathrm{l}$; and haemin/menadione solution (Gibco) $10 \mathrm{ml} / \mathrm{l}$. This medium was dispensed into universal containers and autoclaved at $121^{\circ} \mathrm{C}$ for $15 \mathrm{~min}$.

A similar medium was prepared for the determination of $\mathrm{H}_{2} \mathrm{~S}$ production, with the addition of ammonium ferrous sulphate $(0.6 \mathrm{~g} / \mathrm{l})$ and sodium thiosulphate $(0.4 \mathrm{~g} / 1)$.

\section{Substrates}

The following substrates were prepared as $20 \%$ (wt/vol) aqueous solutions: arabinose, cellobiose, fructose, glucose, inositol, lactose, maltose, mannitol, mannose, melezitose, raffinose, ribose, salicin, sorbitol, sucrose, trehalose and xylose. Aesculin and starch were prepared as $2 \%$ (wt/vol) aqueous solutions. All solutions were steamed once for $20 \mathrm{~min}$ before use and stored at room temperature.

\section{Preparation of microtitre tray}

Sterile U-bottomed microtitre trays (Sterilin, Teddington) were divided into four sections each comprising 24 wells. Using 50-dropper pipettes, $20 \mu \mathrm{l}$ of each of the substrate solutions was dispensed into the appropriate wells in each of the four sections. In addition two extra wells, containing one drop of aesculin and starch solutions respectively, were included in each section; $100 \mu$ l of the basal medium was then added to each of 23 wells in the four sections of the tray. The remaining four wells were filled with $100 \mu \mathrm{l}$ of the $\mathrm{H}_{2} \mathrm{~S}$ base. Thus in each section of the tray, 19 wells were used to investigate fermentative ability, two for determination of aesculin and starch hydrolysis, one for $\mathrm{H}_{2} \mathrm{~S}$ production, and two acted as control wells. 
Identity of strains examined in this study

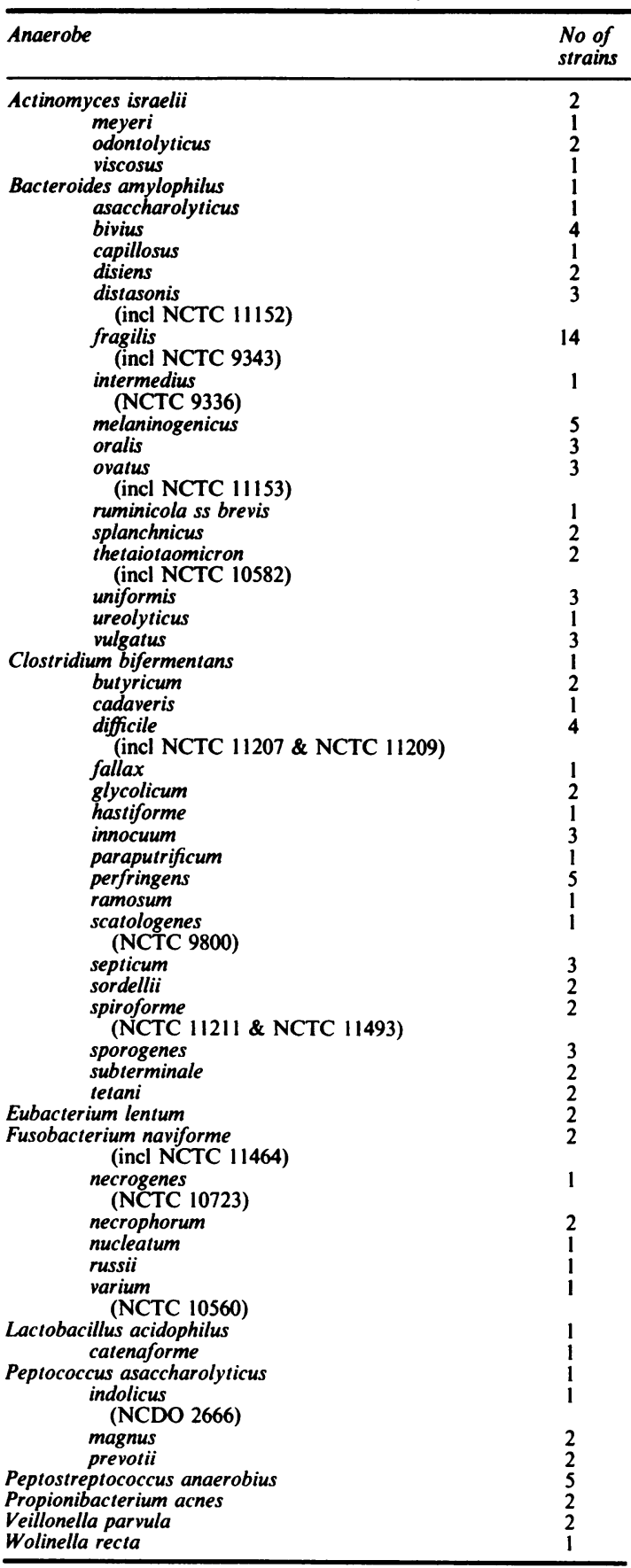

Organisms to be tested were cultured anaerobically on commercially prepared horse blood agar plates
(Lab M) for $48 \mathrm{~h}$ at $37^{\circ} \mathrm{C}$. Growth was removed with a straight wire and stabbed into each well. The tray was then covered with a perforated sterile plastic film (Seward) and incubated at $37^{\circ} \mathrm{C}$ for $48 \mathrm{~h}$ in an anaerobic jar. The gas mixture used contained hydrogen $(90 \%)$ and carbon dioxide $(10 \%)$, and the evacuation/replacement technique of Willis ${ }^{7}$ was followed, resulting in a final concentration of $7 \% \mathrm{CO}_{2}$.

After incubation the microtitre trays were taken from the jar and the plastic seals removed. One drop of $0.04 \%$ bromothymol blue indicator was placed in each of the fermentation and control wells to determine acid production. A bright yellow colour indicated strong acid production, and weaker reactions were determined by reference to the control wells. Hydrolysis of aesculin and starch was determined by the addition of one drop of $1 \%(\mathrm{wt} / \mathrm{vol})$ ferric citrate solution or one drop of Jensen's iodine respectively to the appropriate wells. Production of hydrogen sulphide was indicated by blackening of the medium in the $\mathrm{H}_{2} \mathrm{~S}$ well.

\section{CONVENTIONAL PLATE METHOD FOR}

FERMENTATION REACTIONS

The method used was that of Phillips. ${ }^{1}$ Blood agar plates were poured containing Anaerobe Identification Medium (Lab M Lab 66) and 6\% defibrinated horse blood. The plates were dried and then flooded with $1 \mathrm{ml}$ of $20 \%$ carbohydrate solution as required. After drying, plates were divided with a sterile scalpel and spot inoculated with the organisms under test. Following incubation anaerobically at $37^{\circ} \mathrm{C}$ for $48 \mathrm{~h}$ plugs of agar were withdrawn from each segment; two drops of $0.04 \%$ bromothymol blue indicator were then added to each plug in order to determine acid production.

\section{INDOLE PRODUCTION}

Production of indole was determined both by the addition of Kovac's reagent to indole/nitrite medium (BBL), and by the use of the para-dimethylaminocinnamaldehyde spot test. ${ }^{8}$

\section{NITRATE REDUCTION}

Reduction of nitrite was determined both in indole/nitrite medium (BBL) and by the use of nitrate/molybdate discs. ${ }^{9}$

GAS CHROMATOGRAPHIC ANALYSIS OF METABOLIC END-PRODUCTS

A Pye Unicam series 104 gas chromatograph equipped with a flame ionisation detector was used, employing a $1.5 \mathrm{~m} \times 4 \mathrm{~mm}$ id glass column packed with $10 \%$ FFAP on diatomite CLQ (JJ's chromatography). The oven temperature was $150^{\circ} \mathrm{C}$ and the carrier gas was nitrogen at a flow rate of $50 \mathrm{ml} / \mathrm{min}$. 


\section{Microtitre determination}

After the determination of acid production the contents of the fructose and glucose wells were withdrawn and mixed in a test tube. After acidification with $\mathbf{0 . 2}$ $\mathrm{ml} 50 \% \mathrm{H}_{2} \mathrm{SO}_{4}$ short chain fatty acids were extracted in $0.4 \mathrm{ml}$ diethyl ether. Aliquots $(2 \mu \mathrm{l})$ were analysed by gas-liquid chromatography (GLC) as described above.

\section{Standard procedure for GLC analysis}

Cooked meat broths containing dried meat granules (LabM Lab24) $37.5 \mathrm{~g} / \mathrm{l}$; Brain Heart Infusion (LabM Lab49) $17.5 \mathrm{~g} / \mathrm{l}$; yeast extract (Oxoid L21) $6 \mathrm{~g} / \mathrm{l}$; glucose $5 \mathrm{~g} / \mathrm{l}$ and haemin/menadione solution (Gibco) 10 $\mathrm{ml} / 1$ were dispensed into universal containers and autoclaved at $121^{\circ} \mathrm{C}$ for $15 \mathrm{~min}$. Inoculated broths were incubated at $37^{\circ} \mathrm{C}$ for $48 \mathrm{~h}$. One ml of broth was removed, acidified with $0.2 \mathrm{ml} 50 \% \quad \mathrm{H}_{2} \mathrm{SO}_{4}$ and extracted with $1 \mathrm{ml}$ diethyl ether. Samples $(1 \mu \mathrm{l})$ were analysed as described above.

\section{ADDITIONAL TESTS}

Tests such as gelatin hydrolysis, ${ }^{10}$ and reactions on egg yolk agar $^{7}$ were performed on agar plates. Bile sensitivity was performed as a disc test in both miniaturised and conventional systems. Sterile filter paper discs were impregnated with $25 \mu$ l sterile $20 \%$ bile salts solution. After drying at room temperature for 3 days, discs were placed on blood agar purity plates and incubated anaerobically at $37^{\circ} \mathrm{C}$ for $48 \mathrm{~h}$.

\section{Results}

All 121 isolates were definitively identified by the microtitre tray method, in conjunction with GLC endproducts analysis, using the data of Holdeman et $\mathrm{al}^{2}$ as a source of test results. Moreover the gas chromatograms obtained from the microtitre tray cultures were qualitatively and quantitatively similar to those derived from standard cooked meat broth cultures.

The correlation observed between biochemical test results obtained in the microtitre tray method and those published by Holdeman et $a l^{2}$ was $97 \%$; the correlation between results derived from the plate method $^{1}$ and those of Holdeman et al ${ }^{2}$ was $97.5 \%$.

There was $100 \%$ agreement between the two nitrate reduction tests, and a similar correlation was noted between the results obtained from the two tests for the production of indole.

\section{Discussion}

Miniaturised methods for the identification of anaerobes offer several advantages, these being largely related to the potential saving in time, media and materials. ${ }^{6}$ Commercial kits offer even greater economies of time than laboratory-prepared media, but are significantly more expensive.

The degree of miniaturisation depends to some extent upon the number of strains to be identified in each batch. The micromethod of Wilkins and Walker ${ }^{5}$ can accommodate 48 isolates per tray, and trays are both filled with media and inoculated with automated apparatus. This method is clearly unsuited to the identification of small numbers of anaerobic isolates, whereas the method described in this communication can be used with as few as four isolates at a time. Commerical kits can however be used to identify isolates singly.

The microtitre tray method described here was prepared, and inoculated on the open bench, and incubated in anaerobic jars, and is thus eminently suitable for use in any clinical laboratory. The basal medium employed is similar to PY broth; ${ }^{2}$ initially this broth was used, but three saccharoclastic isolates of Bacteroides spp were found to produce acid in all wells, including controls. Reduction of the yeast extract concentration to $0.6 \%$ represents a compromise which eliminates this problem, without interfering with growth requirements of more delicate organisms. Incorporation of agar into the basal medium and inoculation of the medium by stabbing enables the degree of growth to be reliably estimated.

Commercial test systems which employ fermentation tests as their principal component often fail to accurately identify asaccharolytic organisms. Hanson et $a l^{11}$ compared API and Minitek systems for the identification of clinical anaerobic isolates, and found that both systems produced an identification for only $51 \%$ of strains. Moreover, these identifications were found to differ in $16 \%$ of cases. The Flow AnaerobeTek system correctly identified $70 \%$ of 204 common anaerobes $^{12}$ and $85 \%$ of 216 strains examined by Buesching et al. ${ }^{13}$

To resolve this well recognised problem, a selected range of tests is employed in additiion to those performed in microtitre trays. Where possible these tests are performed on agar plates (bile sensitivity, nitrate reduction) or as rapid tests, such as the indole spot test. This has been evaluated both for aerobes ${ }^{14}$ and anaerobes, ${ }^{8}$ and in both cases $p$-dimethylaminocinnamaldehyde was found the most sensitive and accurate reagent for indole spot-testing.

A recently described technique for the identification of anaerobes employs discs of fermentable substrates placed upon agar plates. ${ }^{15}$ However, this method utilises a range of substrates more limited than the present microtitre tray method, and the preparation of a multiplicity of different discs is as laborious as the performance of a standard plate method. ${ }^{1}$ Both the plate method and the miniaturised method described here offer highly accurate identification of a wide 
range of anaerobic species, while the miniaturised method offers considerable economies of time and effort.

I wish to thank Dr AT Willis for his critical reading of the manuscript.

\section{References}

${ }^{1}$ Phillips KD. A simple and sensitive technique for determining the fermentation reactions of non-sporing anaerobes. $J$ Appl Bacteriol 1976;41:325-8.

${ }^{2}$ Holdeman LV, Cato EP, Moore WEC. Anaerobe laboratory manual 4th ed. Blacksburg: Virginia Polytechnic Institute, 1977.

${ }^{3}$ Dowell VR, Hawkins TM. Laboratory methods in anaerobic bacteriology. Washington, DC: US Government Printing Office, 1978.

4 Sutter VL, Citron DM, Finegold SM. Wadsworth anaerobic bacteriology manual 3rd ed. St Louis: CV Mosby, 1980.

${ }^{5}$ Wilkins TD, Walker CB. Development of a micromethod for identification of anaerobic bacteria. Appl Microbiol 1975;30: 825-30.

6 Jayne-Williams DJ. Miniaturised methods for the characterization of bacterial isolates. J Appl Bacteriol 1975;38:305-9.

7 Willis AT. Anaerobic bacteriology: clinical and laboratory practice 3rd ed. London: Butterworth, 1977.
${ }^{8}$ Sutter VL, Carter WT. Evaluation of media and reagents for indole-spot tests in anaerobic bacteriology. Am J Clin Pathol 1972;58:335-8.

${ }^{9}$ Wideman PA, Citronbaum DM, Sutter VL. Simple disk test for detection of nitrate reduction by anaerobic bacteria. $J$ Clin Microbiol 1977;5:315-9.

${ }^{10}$ Frazier WC. A method for the detection of changes in gelatin due to bacteria. J Infect Dis 1926;39:302-9.

" Hanson CW, Cassorla R, Martin WJ. API and Minitek systems in identification of clinical isolates of anaerobic Gram-negative bacilli and Clostridium species. J Clin Microbiol 1979;10:14-8.

12 Lombard GL, Whaley DN, Dowell VR. Comparison of media in the Anaerobe-Tek and Presumpto Plate systems and evaluation of the Anaerobe-Tek system for identification of commonly encountered anaerobes. J Clin Microbiol 1982;16:1066-72.

${ }^{13}$ Buesching WJ, Svirbely JR, Ayers LW. Evaluation of the Anaerobe-Tek system for the identification of anaerobic bacteria. J Clin Microbiol 1983;17:824-9.

${ }^{14}$ Miller JM, Wright JW. Spot indole test: evaluation of four reagents. J Clin Microbiol 1982;15:589-92.

is Occhionero M, Luzzi I, Mastrantonio P, Panichi G, Pantosti AL. A note on fermentation reactions of anaerobic bacteria on a solid medium. J Appl Bacteriol 1982;52:449-551.

Requests for reprints to: PN Levett, Anaerobe Reference Unit, Public Health Laboratory, Luton and Dunstable Hospital, Lewsey Road, Luton LU4 0DZ. 